\section{Economía popular, producción popular y desafíos tecnocientíficos}

Resumen: Este trabajo desarrolla una breve historia de la génesis del espacio denominado "economía popular" y expone las debilidades notorias de la política pública para entender, abordar y proponer soluciones para los problemas de los más débiles. Es inevitablemente provocador, ya que cuestiona el uso del término "economía popular" con su alcance actual y propone en su lugar el concepto de "producción popular" para ampliar su alcance social y su valor como instrumento transformador. Presenta una propuesta de nueva caracterización abarcadora y un esbozo de formulación metodológica para cambiar la mirada, hacia una economía basada en la atención de necesidades comunitarias, que podamos llamar economía popular. Discute finalmente el posible aporte del complejo de ciencia y técnica nacional al desarrollo de la producción popular.

Palabras clave: Economía popular; producción popular; equidad social; tecnología para la producción popular; trabajo pleno.

Popular economy, popular production and technoscientific challenges

Abstract: This work develops a brief history of the genesis of the space called "popular economy" and exposes the notorious weaknesses of public policy to understand, encompass and propose solutions to the problems of the weakest. It is inevitably provocative, since it questions the use of the term "popular economy" with its current scope and, proposes instead, the concept of "popular production" to broaden its social scope and its value as a transformative instrument. It presents a proposal for a new comprehensive characterization and an outline of a methodological formulation in order to change the view towards an economy based on the attention of community needs, which we can call popular economy. Finally, it discusses the possible contribution of the national science and technology complex to the development of popular production.

Keywords: Popular economy; popular production; Social equity; technology for popular production; full job.

\section{Economia popular, produção popular e desafios tecnocientíficos}

Resumo: Este trabalho desenvolve um breve histórico da gênese do espaço denominado "economia popular" e expõe as notórias fragilidades das políticas públicas para compreender, abordar e propor soluções aos problemas dos mais fracos. Ele se propõe como inevitavelmente provocador, uma vez que questiona o uso do termo "economia popular" com o seu âmbito atual e, em vez disso, propõe o conceito de "produção popular" para ampliar seu alcance social e seu valor como instrumento transformador. Apresentaremos nele uma proposta de nova caracterização abrangente e um esboço de formulação metodológica, a fim de propor uma mudança de perspectiva, rumo a uma economia baseada na atenção às necessidades da comunidade. Uma economia que podemos chamar de economia popular. Por fim, discutiremos a possível contribuição do complexo nacional de ciência e tecnologia para o desenvolvimento da produção popular. Palavras-chave: Economia popular; produção popular; Igualdade social; tecnologia de produção popular; trabalho pleno.

\section{Ciencia Tecnología y Política \\ Año 3 N$^{\circ}$ Noviembre 2020}

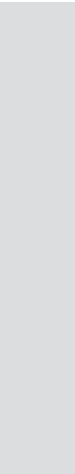

Enrique Mario
Martínez
Ingeniero

Coordinador del Instituto para la Producción Popular

ippenrique@gmail.com

Año $3 N^{\circ} 5$ Noviembre 2020

Fecha de recibido: 27/07/2020

Fecha de aprobado: 28/08/2020 https://doi.org/10.24215/26183188e042 https://revistas.un|p.edu.ar/CTyP ISSN 2618-3188

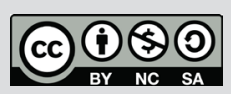

Esta obra está bajo licencia Creative Commons Atribución-NoComercial-Compartirlgual 4.0 Internacional http://creativecommons.org/licenses/bync-sa/4.O/deed.es_AR 


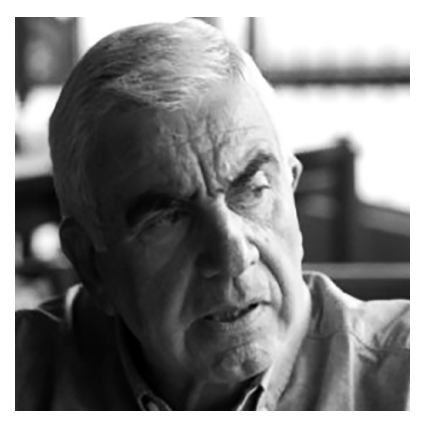

\section{Enrique Mario Martínez}

Ingeniero

Coordinador del Instituto

para la Producción Popular

ippenrique@gmail.com

\section{Economía popular, producción popular y desafíos tecnocientíficos}

Resumen: Este trabajo desarrolla una breve historia de la génesis del espacio denominado "economía popular" y expone las debilidades notorias de la política pública para entender, abordar y proponer soluciones para los problemas de los más débiles. Es inevitablemente provocador, ya que cuestiona el uso del término "economía popular" con su alcance actual y propone en su lugar el concepto de "producción popular" para ampliar su alcance social y su valor como instrumento transformador. Presenta una propuesta de nueva caracterización abarcadora y un esbozo de formulación metodológica para cambiar la mirada, hacia una economía basada en la atención de necesidades comunitarias, que podamos llamar economía popular. Discute finalmente el posible aporte del complejo de ciencia y técnica nacional al desarrollo de la producción popular.

\section{Introducción}

Intentamos en este trabajo entender los alcances de la economía popular, sus orígenes, la compatibilidad entre la subjetividad de los actores y análisis pretendidamente objetivos, los posibles escenarios futuros y el aporte que podría hacer el complejo científico tecnológico nacional.

Se trata de una tarea necesaria, porque el término "economía popular" es de reciente incorporación al léxico social. Es más, no surge de la academia o de círculos burocráticos, sino de protagonistas sociales que han buscado definir una identidad para sí y para el resto de la sociedad. Hacia principios del siglo actual se produjo una crisis social de extrema gravedad en el país, porque sumó una inestabilidad económica aguda a una ausencia de autoridad o liderazgo político poco frecuente, al punto que a la renuncia del Presidente constitucional, le sucedieron Presidentes provisorios elegidos y renunciados en una secuencia de días. La 
última designación provisoria, la del Dr. Eduardo Duhalde, condujo a regularizar el gobierno a través de elecciones generales, pero aun así, los plazos debieron anticiparse en medio de un clima de convulsión política cotidiana. Los resultados de las elecciones generales reflejaron esa pérdida de legitimidad y de referencia de las dirigencias, con la gran dispersión de votos y con una definición truncada en segunda vuelta, que llevó a que Néstor Kirchner asumiera legítimamente, pero con menos del $23 \%$ de los votos totales.

En definitiva, el gobierno que asumió el 25 de mayo de 2003 encontró una base social sin integración al trabajo registrado o cualquier otro; irritada por la falta de contención y de respuesta al reclamo de varios años; que justamente por ese prolongado tránsito tenía un principio de organización, que le permitía reclamar alimentos o asistencia económica, a la vez que el derecho a ser considerados interlocutores.

Se sumaron cooperativas de trabajo textil o alimenticio; cartoneros, que se agruparon en el llamado Movimiento de Trabajadores Excluidos; movimientos campesinos; productores de hortalizas en el cinturón del AMBA, sin propiedad de la tierra; artesanos de venta callejera; vendedores ambulantes; motoqueros. A ellos se agregaron habitualmente los entornos familiares y los identificó la frecuente presencia en la calle.

Por boca de sus propios integrantes, apareció la economía popular.

\section{Una necesaria discusión semántica}

El colectivo no eligió un nombre de fantasía, a los fines exclusivos de identificarse. Economía popular debiera caracterizar a la administración de los recursos y necesidades de un universo social que se identifica como "el pueblo". Sin ánimo ni espacio para incursionar en la filosofía política, parece claro que asignar la representación popular al universo de trabajadores someramente descrito más arriba constituye una petición de principio, que tiene un efecto más negativo que positivo.

Por la positiva, tiene un impacto en la presencia en cualquier mesa política o administrativa de cualquier gobierno. Le agrega valor.

Por la negativa, construye un cerco de desconfianza, que lleva hacia el rechazo, con todo otro ámbito que se considere a la vez pueblo y perjudicado por las políticas económicas y sociales, aunque éstas no lleven su situación a niveles críticos de marginación. El conflicto no se plantea en los términos clásicos y conocidos de identidad de clase, ya que la categoría pueblo no lo es. Se da en el espacio de la subjetividad de millones de compatriotas, que creen legítimamente pertenecer al pueblo postergado y sin embargo, advierten que hay una categoría económica que no los contiene adecuadamente. Es aceptable hablar de la economía doméstica; de una provincia; de cualquier identidad homogénea, partiendo de admitir que se trata de un espacio acotado dentro de la economía nacional, en la cual interactúan las más diversas miradas. Pero no de economía popular, con solo parte del pueblo en ella.

Corriendo el riesgo simétrico, al plantear un concepto desde la abstracción y luego vincularlo con la economía real, preferimos hablar de producción popular.

Producción popular es aquella que se aplica a obtener bienes o brindar servicios, con el fin de atender necesidades comunitarias (esto es: del pueblo), poniendo el lucro en un segundo plano 
y por ende alejándose de la escala de valores típica del capitalismo'.

¿Quiénes quedan encuadrados en esta caracterización?

Todos aquellos que objetivamente anteponen la atención de las necesidades comunitarias a la búsqueda de un beneficio personal o grupal; sea porque esa es la decisión consciente y deliberada del emprendimiento; sea porque sus relaciones con los demás actores de la economía los llevan a buscar la subsistencia, sin posibilidad de extraer valor de otro segmento de una cadena de valor y lucrar con el trabajo de otros. Son quienes objetivamente ponen o deben poner el lucro en segundo plano, más allá de su propia subjetividad. Este universo laboral tiene identidad; tiene una meta general común; puede crecer, por razones vegetativas o a expensas de otro sector rentístico o capitalista estándar.

Así definida, la producción popular incluye todas las actividades que se incluyen en el menú de la "economía popular". Se suman a ese universo todos los trabajadores independientes que no disponen de ningún espacio de apropiación de renta, o sea todos los prestadores de servicios personales, excluidos los protegidos por normas institucionales expresas y que disponen de privilegios en el desempeño de su actividad, como típicamente sucede con los abogados. El Covid19, indirectamente, se encargó de dejar en evidencia a este colectivo de la población económicamente activa (PEA), a los cuales ni el Estado ni los empresarios, atiende ni asiste y que cuando la economía se detiene, quedan a la intemperie bruscamente, sin ingreso alguno². Finalmente, también incluye a toda la economía social y solidaria, en tanto esta pertenencia se dé por los inte- reses subjetivos y objetivos del emprendimiento y no solo por distribuir de manera más equitativa los beneficios generados en una actividad integrada al modo capitalista normal. La homogeneidad conceptual es clara. La dificultad notoria se concentra en la ausencia absoluta de tratamiento sistemático del sector en los términos expuestos, por lo que no se cuenta con estadísticas, análisis de comportamiento ni elementos similares que permitan definir políticas públicas al respecto.

\section{La representación de la producción popular}

A la fecha, como se señaló, la identidad, la visibilidad y por ende la representación de la producción popular es una asignatura pendiente, de necesaria elaboración.

Solo ha avanzado la fracción auto titulada como economía popular. En 2011 se creó la Confederación de Trabajadores de la Economía Popular (CTEP) que buscó aglutinar los esfuerzos de varios movimientos sociales en tres grandes planos: el reclamo por situaciones de inequidad social, tanto puntuales como estructurales; la interlocución con las áreas de gobierno que administran la asistencia social; el ejercicio de una representación sindical o para-sindical de trabajadores del espacio, para acceder a derechos análogos a los de trabajadores registrados (Muñoz y Villar, 2017). Una somera descripción, seguramente incompleta, marca los avances conseguidos:

- De 5 organizaciones fundadoras, la adhesión creció hasta superar las 30, con las fortalezas que ello implica y con alguna generación lógica de controversias internas.

- Se creó la Mutual Sentimiento, que brinda prestaciones médicas a los monotributistas y mono-

\footnotetext{
1 Ver para profundizar en ello: Martínez (2017)

${ }^{2}$ Ver para profundizar en ello: Martínez (2020).
} 
tributistas sociales del sector.

- En los últimos días del gobierno de Cristina Fernandez de Kirchner (2015), se consiguió el reconocimiento del Ministerio de Trabajo como entidad social. Figura sui generis, ya que no se otorgó el derecho a considerarse trabajador con vinculación con el Estado, o un estatuto especial para los trabajadores sin relación de dependencia.

- En 2016, luego de buscar y conseguir alianzas políticas y gremiales de envergadura, aún con la Confederación General del Trabajo (CGT) se consiguió que el Congreso nacional aprobara una Ley de Emergencia Social, que otorgó fondos de relevancia para asistir a los más desprotegidos.

- En 2019, se creó la Unión de Trabajadores de la Economía Popular (UTEP), que busca ser considerada miembro de la CGT y representar orgánicamente a los trabajadores del sector.

- A partir de diciembre de 2019, con el acceso al gobierno del Frente de Todos, un espacio político expresamente comprometido con la atención y corrección de inequidades sociales, se sumaron a espacios de gestión y a escaños legislativos representantes de los movimientos sociales, administrando ámbitos de asistencia social y con capacidad de tomar iniciativas legislativas transformadoras.

- Durante 2020, la primera medida originada en esa nueva forma de representación fue la creación del Registro Nacional de Trabajadores de la Economía Popular (RENATEP), para un universo de trabajadores impreciso, que comprende las actividades históricas agrupadas en la CTEP y toma en cuenta la condición de que los solicitantes tengan un patrimonio muy bajo y, en caso de tener ocupación en relación de dependencia, que ésta implique salarios por debajo del salario mínimo vital. O sea: categóricamente asocia la idea de trabajador de la economía popular a pobre, o incluso indigente. Este registro, todo indica, es el paso previo al intento de otorgar a los ingresados un salario universal básico.

Este ha sido el camino esforzado y comprometido de quienes representan a una fracción de la producción popular, en un país que desde la fundación de la CTEP tuvo un aumento de la pobreza sustancial, abarcando al presente entre 40 y $45 \%$ de la población. Justamente la imprecisión de estos números es lo que necesita explicación con algún detalle.

\section{El presente}

A riesgo de ser reiterativo, creo necesario reforzar que existe una confusión conceptual, acerca de la situación de aquellos más perjudicados por la globalización y concentración del capitalismo.

Hablamos de economía popular y es un término que no abarca el colectivo necesario, ni una parte precisa del mismo. Sostengo que la producción popular es la idea a profundizar y afianzar, y sin embargo es claro que ella no forma parte de ningún ámbito académico ni filosófico de relevancia en que se analice el trabajo y sus perspectivas en el país o en el mundo.

No es de extrañar que ante semejante madeja, que termina siendo sinónimo de debilidad, ni siquiera contemos con cifras estadísticas que puedan servir de algún punto de apoyo.

Para muestra, se pueden analizar las estadísticas sobre ocupación y desocupación publicadas por el Instituto Nacional de Estadística y Censos (IN$\mathrm{DEC})$.

Desde hace mucho tiempo el mundo del trabajo se estudia por una encuesta trimestral, la Encuesta Permanente de Hogares (EPH), que abar- 
ca un conjunto de aglomerados urbanos, que en este momento son 31. Analizando las cifras del año 2019, se advierte que la población total comprendida es de 28.200.000 personas, aproximadamente. Sobre ese total es que la encuesta releva lugar por lugar, la población económicamente activa, la ocupación, desocupación, los asalariados con o sin descuento jubilatorio, los no asalariados. Las cifras se extrapolan luego al total nacional.

Ahora bien, la población del país en 2019 era de alrededor de 44.500 .000 personas. Es decir, con la información del $63.3 \%$ de la población se concluye lo que sucede en el 100\%. Se podría afirmar que la representatividad estadística de la muestra es enormemente abarcadora y sus conclusiones se pueden extender al universo sin dificultad alguna.

Sin embargo, no es así. No se trata de una muestra representativa del universo. Por el contrario, deliberadamente se hace un sesgo eligiendo los centros más poblados de la Argentina, al punto tal que el $80 \%$ de la muestra está compuesto por aglomerados con más de 500.000 habitantes y el 20\% con menos de 500.000. Estos últimos corresponden, en casi todos los casos, a los centros administrativos de provincias con la menor densidad poblacional del país, para asegurar así una representación distrital adecuada.

Esta metodología construye un hecho cultural falso: que los grandes centros urbanos tienen una estructura ocupacional similar a los pueblos y ciudades más pequeñas del país. La encuesta de la cual se deduce la situación ocupacional de los argentinos, postula que 16.300 .000 personas que viven en localidades de menos de 500.000 habitantes tienen una organización social y productiva; una estructura de servicios sociales y personales; un sistema de transporte; un siste- ma de esparcimiento; de atención de la salud y la educación; similares al promedio de 28 millones de personas que viven en aglomerados urbanos mayores. Lo aceptan los economistas, los sociólogos, los dirigentes políticos. Pero cualquiera que se tome el trabajo de examinar algunos pocos datos objetivos y subjetivos de ese $37 \%$ de la población a la que no se mide, al menos debería concluir que debemos estudiar el tema más a fondo. Bien a fondo.

Es importante entender si ese análisis modificará sustancialmente los datos de la población económicamente activa y de la ocupación y desocupación que tiene el país. Más importante, sin embargo, es entender que así como reiteradamente se señalan diferencias sustanciales entre lugares tan próximos y con vasos comunicantes simples, como la Ciudad Autónoma de Buenos Aires y el Gran Buenos Aires, e incluso entre barrios de la Capital Federal, una política productiva nacional necesita conocer con mucho más cuidado detalles de la estructura del trabajo en el interior del país, por supuesto admitiendo ab initio grandes diferencias entre las ciudades misioneras o cordobesas o cualquier otra, que deben ser tipificadas, en un panorama general que permita apoyar de manera efectiva la producción popular y contener a los pobres hasta que dejen de serlo.

A partir de una base de conocimiento y de información tan endebles, no debe llamar la atención en absoluto la insólita sorpresa de un gobierno nacional con compromiso social, que ante las consecuencias económicas de la crisis sanitaria que se ha transitado decidió aportar un ingreso familiar de emergencia (IFE) bajo ciertas condiciones y con las estadísticas disponibles, recibiendo pedidos para 8 millones de personas más de las esperadas. Ojalá a breve plazo se conozca la distribución geográfica de esas solicitudes, algu- 
na mínima historia laboral de esos compatriotas y comiencen trabajos que expliquen el pasado y presente de trabajo de ese universo y ayude a proyectar su futuro.

\section{Para adelante}

Se trata de alcanzar una meta superior a la representación sindical de los trabajadores independientes o excluidos; al establecimiento de un sistema de ingreso básico que asegure superar un piso mínimo de indigencia a millones de personas sin otras opciones; al inventario detallado de comedores populares y la garantía de su abastecimiento. Estas medidas son claramente valorables y elogiables, pero todas ellas tienen un denominador común que les construye un horizonte limitado: están pensadas y ejecutadas en el contexto estructural que creó el problema, sin cambiar ese escenario, sino buscando atenuar los efectos. Es evidente que por esa vía no se interrumpe el flujo de marginados y excluidos.

Se trata, en verdad, de construir un escenario de trabajo diferente para alrededor del 50\% de la población económicamente activa del país, o sea entre 10 y 11 millones de personas, con la tasa de actividad actual, o entre 13 y 14 millones, si la proporción de adultos trabajando se acercara a un país europeo medio.

Ésta no solo es la meta equitativa para esos compatriotas sino también sería un sano punto de inflexión para las políticas asistenciales y para las políticas productivas de una Nación que siempre ha aspirado a ser un foco conceptual en la región. Esta aspiración significa recorrer caminos de desarrollo diferentes de los hasta ahora intentados, que se pueden esquematizar como:

- Formar trabajadores en conocimientos técnicos y administrativos, básicos, medios y superiores.
- Convocar inversores nacionales y extranjeros a disponer de ese stock de trabajadores, sumarlo a recursos naturales disponibles y agregar tecnología ya disponible por el inversor, con el fin de producir bienes o servicios.

- El resultado de la aparición y crecimiento de actividades prósperas, derramaría en proveedores, clientes y dependientes, mejorando la condición de vida general.

El Estado y la comunidad crean así condiciones favorables y los inversores son los tractores del desarrollo.

Seguramente, por esta vía se han hecho muy buenos negocios en el país. Lo concreto y a la vista es que el deterioro de la calidad de vida de la base de la pirámide de ingresos familiares ha sido creciente; que el mayor salario real se alcanzó en 1974 y desde entonces ha sido menor o mucho menor a esa referencia; la desocupación considerada exitosa hoy es el doble de la estándar en 1983; la pobreza supera el 40\%. Pueden acumularse indicadores sociales globales. No podemos decir lo mismo con el detalle sectorial o local, porque por lo señalado más arriba la información y los estudios disponibles son pobres.

El estado de situación alcanzado supera la posibilidad de compensar con ingresos a los perdedores. Ni con ingresos aportados por rentas generales ni por impuestos específicos a las grandes riquezas.

Más que distribuir mejor los frutos, debemos concebir el modo de distribuir mejor el trabajo, integrando a ese 50\% de muy baja productividad global en actividades que les compensen por sí mismas el deterioro actual.

A diferencia de la secuencia intentada y fracasada de manera reiterada, debería apelarse a una aproximación más profunda, que tenga en cuenta 
las causas primarias de tamaño problema.

Eso llevará a configurar un aparato productivo de bienes y servicios que crezca y se consolide en paralelo al que el lucro, como valor esencial, ha definido.

Se trata de un sistema concebido para satisfacer las necesidades comunitarias de un modo sustentable y que no genere marginados o excluidos.

\section{Ésa es la producción popular.}

A partir de ese escenario, podríamos decir también que ésa es la economía popular dentro del sistema económico global.

Como se ve, la diferencia metodológica no es menor. Se trata de definir un subsistema por sus metas y valores, en este caso la atención sustentable y sin marginados de las necesidades comunitarias, no por sus integrantes. Sobre todo, se trata de evitar que los excluidos del capitalismo rentístico y concentrador sean considerados como un subsistema permanente, por el atributo de ser excluidos y haber desarrollado instrumentos de supervivencia que en el mejor de los casos permiten comer, pero no emerger de la pobreza.

\section{Las discusiones esenciales}

En el contexto expuesto aparece la necesidad de contestar varias preguntas como condición necesaria previa a la formulación de planes productivos. En todo caso, esas preguntas deben responderse para validar los planes.

- ¿Cuáles son las asignaturas pendientes en la atención de necesidades comunitarias, con un detalle por gran área de actividad?

- ¿Cuáles necesidades comunitarias se están atendiendo con mecanismos de mercado que deterioran la calidad de vida de fracciones importantes de la sociedad? ¿Por qué?
- ¿Qué necesidades comunitarias admiten la participación descentralizada de los compatriotas, lugar por lugar, sin afectar la calidad de la prestación o mejorándola?

- ¿Cuáles son los factores de producción -tierra, trabajo calificado, capital, tecnología- ausentes o que deben ser fortalecidos, para permitir la atención de las necesidades comunitarias a escala local? ¿Cómo puede el sistema público o privado cubrir esas falencias?

- ¿Están dadas las condiciones de sustentabilidad del proyecto, que aseguren que la comunidad en su gran mayoría ha de hacerlo propio?

No se trata de preguntas habituales, ni en la formulación de proyectos privados, ni lamentablemente en la formulación de proyectos generados desde el Estado. Sin embargo, son las que llevan simultáneamente a elevar la calidad de vida general y a acercarse a la plena ocupación eficiente de las y los compatriotas.

Seguramente, las respuestas iniciales generan una cadena extensa de preguntas y respuestas posteriores; el tratamiento es de naturaleza diversa en grandes conglomerados y en localidades más pequeñas; pero la medida del éxito es la misma para cada ámbito comunitario, de cualquier dimensión y en cualquier espacio geográfico. Es útil lo que atiende necesidades comunes.

Este trabajo debe ser considerado una etapa elemental y previa de una descomunal tarea pendiente: poner la economía popular en sus justos términos y convertirla en una propuesta alternativa real frente al capitalismo concentrado, separándose de la mirada en que las reacciones son actitudes defensivas frente a una distribución ominosa de los frutos del trabajo colectivo.

No se rechaza aquí la asistencia a los más necesitados. Por el contrario, se la considera esencial, 
pero se evita catalogarla como la solución de los problemas. Toda acción dentro de las estructuras vigentes no puede ser considerada solución, sino paliativo. La transformación estructural, en cambio, necesita con urgencia nuevos actores, que con nuevos instrumentos, encaren los viejos problemas con nuevas miradas.

\section{El posible aporte del complejo de ciencia y técnica}

En este marco resulta importante discutir el posible aporte a las tareas planteadas, del complejo científico-tecnológico nacional. Para ello tal vez sea conveniente diferenciar las posibles contribuciones que podrían hacerse desde las ciencias sociales, de aquellas que podrían provenir desde las llamadas ciencias exactas.

Los cientistas sociales se han ocupado con fuerza de la llamada "economía popular". En última instancia, se trata de un espacio que refleja con toda intensidad inequidades generadas por el capitalismo de mercado. Lamentablemente, las investigaciones se han orientado a calificar y cuantificar los daños sociales y a explorar caminos de asistencia e inclusión, con variados niveles de aporte de los ámbitos públicos.

La construcción de escenarios nuevos no ha recibido la atención que permita construir propuestas alternativas a la inclusión. La autogestión, aplicada a la solución de problemas comunitarios, se ha considerado como meta teórica, pero no ha sido sometida hasta acá, suficientemente, a los análisis de campo que permitan fortalecer un modelo alternativo. Se trata de una tarea pendiente.

Las ciencias exactas y las ingenierías, a su vez, necesitan cambiar sustancialmente su mirada si es que han de hacer aportes efectivos en el área. El desarrollo de tecnología para la producción po- pular y en particular la organización productiva en pequeña escala, ocupan un lugar marginal en los programas de trabajo de organismos como INTA (Instituto Nacional de Tecnología Agropecuaria), INTI (Instituto Nacional de Tecnología Industrial) - CNEA (Comisión Nacional de Energía Atómica). Sin embargo, las cadenas de valor para producir alimentos o indumentaria que lleguen a los consumidores sin distorsiones de precio; la fabricación de materiales de construcción a escala local; la industria artesanal eficiente, que valorice el aporte humano, pero sume la preocupación por la alta productividad; la automatización de procesos sencillos en emprendimientos cooperativos, el tratamiento de residuos o efluentes, son temas de trabajo con enorme riqueza intelectual, pero no son demandados por la industria concentrada ni por los excluidos del sistema. De la misma manera, el Estado puede armar una empresa de diseminación de la energía renovable en redes barriales, y tratar de poner en el techo, por empezar de cada pobre, paneles fotovoltaicos que le aseguren la disponibilidad de la energía propia, e incluso que tengan excedentes para volcarlo a la red. Eso requiere tecnología y planificación, cosas que están absolutamente al alcance en términos tecnológicos, y por supuesto financiamiento.

Todos estos aspectos requieren del complejo de ciencia y técnica una mirada nueva, que solo provendrá de la toma de conciencia del desafío que está allí, aguardando.

\section{Bibliografía}

Martínez, E. (2017). Ocupémonos. Del Estado de bienestar al Estado transformador. Edición de autor.

Martínez, E. (1 de abril de 2020). Piedra Libre. Agencia Paco Urondo. Recuperado de: https:// 
www.agenciapacourondo.com.ar/opinion/piedra-libre

Muñoz, M. A. \& Villar, L. I. (2017). Confederación de Trabajadores de la Economía Popular (CTEP en la CGT). Entre la organización sindical y el conflicto político-social (Argentina, 2011-2017). Crítica Y Resistencias. Revista De Conflictos Sociales Latinoamericanos, (5), 22-52.

\section{Se presenta a continuación material de lectura complementaria para incursionar en esta te- mática:}

Kelton, S. (2020). The Deficit Myth: Modern Monetary Theory and the Birth of the People's Economy. PublicAffairs

Tcherneva, P. (2020). The case for a job guarantee. Polity

Zuboff, S. (2019). The age of surveillance capitalism. PublicAffairs 